\title{
LOS CELTAS: IDENTIDAD, ETNICIDAD Y ARQUEOLOGÍA
}

\section{THE CELTS. IDENTITY, ETHNICITY AND ARCHAEOLOGY}

\author{
por
}

BEATRIZ DÍAZ SANTANA*

RESUMEN El concepto celta ha sido utilizado hasta la actualidad en un sentido mayoritariamente etnológico. Sin embargo, las teorías vigentes en arqueología sobre la etnicidad y la articulación de ésta en los grupos humanos de la prehistoria hacían esto inviable, al considerar la identidad étnica como una adscripción categórica y homogénea en el espacio y en el tiempo. En este trabajo se revisa el concepto de etnicidad desde la antropología, la lingüística y la arqueología, para finalmente intentar una aplicación de la identidad étnica en la protohistoria del occidente europeo. La etnicidad es un lenguaje de identidades múltiples contingentemente manifestadas, y el medio de establecer una etiología de las redes comerciales del Bronce Final y la Edad del Hierro.

ABSTRACT Celtic concept is often used as an ethnological one. Current theories about ethnicity and its application in Archaeological interpretations make it impossible to determine whether a celtic identity existed in protohistoric past. Problems arise from approaches to ethnicity as a time and space homogeneous essence. This work emphasizes anthropological, linguistic and archaeological approaches to this topic. Western Europe protohistory is my case study. Ethnicity is a language of multiple identities situational and contextually manifested, and a way for an ethiology of Final Bronze Age and Iron Age trade routes.

Palabras claves Etnicidad; identidad, celta; antropología; lenguaje; Bronce Final, Edad del Hierro

Key words

Ethnicity; identity; celtic; anthropology; language; Final Bronze Age; Iron Age.

* Dpto. de Prehistoria. Facultad de Geografía e Historia. Universidad Complutense. Ciudad Universitaria s/n. 28040 Madrid. Email: beatrizdsantana@yahoo.es 


\begin{abstract}
"Virtually every human being belongs to an ethnic group, whether he or she lives in Europe, Melanesia or Central America. There are ethnic groups in English cities, in the Bolivian countryside and in the New Guinea highlands. Anthropologists themselves belong to ethnic groups or nations. Moreover, the concepts and models used in the study of ethnicity can often be applied to modern as well as non-modern contexts, to Western as well as non-Western societies. In this sense, the concept of ethnicity can be said to bridge two important gaps in social anthropology: it entails a focus on dynamics rather than statics, and it relativises the boundaries between "Us" and "Them", between moderns and tribals".
\end{abstract}

Eriksen, T. H. (1993): Ethnicity and Nationalism. London: Pluto Press: 10.

\title{
1. INTRODUCCIÓN
}

No existe en toda la producción historiográfica sobre la protohistoria europea un tema en el que haya mayor consenso que el relativo a la identificación étnica de los celtas. No me refiero a los diferentes grupos que bajo etnónimos de tipo celta (lingüísticamente hablando) aparecen en las Fuentes Clásicas, sino a la imposibilidad de identificar una única etnia celta en el área que los clásicos adscriben a los celtas, y que es al mismo tiempo el área en que se documentan las lenguas historiográficamente denominadas celtas. Este curioso y nada habitual consenso se basa en que, independientemente de nuestras aproximaciones teóricas y metodológicas, la mayoría estamos de acuerdo en que no se puede documentar arqueológicamente una única identidad étnica en el Occidente europeo que responda al concepto celta, tal y como han venido siendo usados los conceptos de celta y de etnia hasta la actualidad.

\section{LOS ORÍGENES}

Este consenso parece establecerse a partir de la aproximación a este tema que Renfrew realizó en 1987 (y seguido, entre otros, por S. James 1999: 73 y G. Ruiz Zapatero 1993: 52 y 2001; Renfrew \& Bahn 1998: 177; Renfrew 1990: 177): "Para que un grupo sea realmente un grupo étnico, tiene que tener conciencia de símismo como tal. El grupo tendrá por consiguiente un nombre para definirse a símismo: un etnónimo." Así, pasan a denominarse celtas las costumbres, la cultura material y el arte de las gentes que habitaban en las zonas en las que se hablaban lenguas celtas (Renfrew 1990: 201), pero ellas y ellos, étnicamente, no eran celtas. Su identidad étnica es algo que se escapa a las posibilidades de análisis de la Arqueología. Existen también otros inconvenientes, como por ejemplo saber hasta cuándo podemos retrotraer el uso de estas lenguas, y sobre todo que tampoco podemos definirlo arqueológicamente (Ruiz Zapatero 1993: 52). Aunque como señala S. James (1999: 81) el mayor inconveniente para esta aplicación del término celta está en que las lenguas celtas son una creación historiográfica, es decir, el término celta fue escogido hace relativamente poco para dotar de un nombre a un conjunto de lenguas. Curiosamente, algo que ya señalara Powell (1958, en Renfrew 1990: 180) para defender todo lo contrario, es decir, que celta tiene un significado etnológico. En este sentido, como afirma James (1999: 81), lo más correcto sería denominarlos "hablantes de las lenguas que nosotros hemos escogido llamar celtas".

Gran parte del problema se encuentra en la visión de la etnicidad aplicada a los estudios de la protohistoria en Arqueología, que ha sido consensuada a partir de la aparición del libro de Renfrew (1990). Renfrew sigue la definición de Dragadze de etnicidad, que es de 1988, pero las fuentes básicas de donde toma este concepto son Narroll y Barth (Renfrew 1990: 191 y 239, n. 7 y 8, Renfrew \& Bahn 1998: 177). La concepción de la etnicidad de Barth, está definida por su interés en desvincular a ésta de las unidades culturales, de concepciones estáticas de la cultura. Para Barth, la definición de los grupos étnicos como unidades culturales 
engloba dos problemas, puesto que: considera a los grupos humanos como unidades aisladas, y con unas fronteras no problemáticas (Eriksen 1993: 37 y ss.). Según Barth, la etnicidad se define no culturalmente, no en nociones de cultura compartida, sino en aquello que es socialmente efectivo en las relaciones interétnicas, en términos de organización social. De todo ello se deriva que los grupos étnicos deben ser definidos desde dentro, desde la perspectiva de sus miembros. Esto, en cuanto atañe a cuestiones cognitivas, es de muy difícil interpretación en Arqueología, a menos que se describa como tal a través de la epigrafía o hubiese quedado constancia a través de las fuentes clásicas. Cosa que, hasta el momento, no ha sucedido, ya que no sabemos si estas gentes del occidente europeo se denominaban a sí mismos como celtas, si bien hay que recordar que tampoco tenemos constancia de lo contrario. En esta línea, se empezó a separar las nociones de cultura compartida de las de identidad, de manera que ambos conceptos han tenido una evolución separada (Sökefeld 1999: 417-418,429). Desde esta perspectiva, la etnicidad es una adscripción categórica consciente, asumida por los propios individuos. Este punto de vista se considera "primordialista" teoría la identidad -o mejor dicho, las identidades, puesto que existe una identidad individual, y una identidad de relación con el o los grupos humanos, que es la que denomino identidad étnica-, son un estado imperativo, un aspecto más o menos inmutable de la persona social (Eriksen 1993: 56). Ante una serie dada de identidades étnicas, esenciales e inmutables, el individuo debe y puede escoger una o varias de ellas. Es una visión estática de la etnicidad que desemboca en cierto determinismo cultural, ya que el individuo está constreñido por su identidad étnica. Además, se le ha criticado a menudo su subjetivismo, puesto que los individuos pueden escoger entre un abanico de identidades determinadas. Esta perspectiva subjetivista se considera una intrusión de la psicología, puesto que presupone que el individuo es libre para escoger cualquier identidad o identidades o por el contrario para ocultarlas, situacionalmente (ibídem: 56). Además, este perspectiva tiene ciertos inconvenientes si se aplica a comunidades con una menor complejidad social y económica, en las que la identidad es mucho más relacional (Hernando 2002) y la individualidad y la agencia ("agency", "self"-Sökefeld 1999: 424 y ss.), y por lo tanto la capacidad individual para escoger, son mucho menores.

Es lógico que Renfrew apoyase esta visión de la etnicidad, porque es una visión procesual de la misma (Eriksen 1993: 38) en la misma línea que el concepto de interacciones entre sistemas políticos similares y los modelos lingüísticos que defiende para explicar la aparición de las lenguas celtas. En la actualidad, esta visión está ampliamente extendida, sobre todo en el mundo anglosajón, y ha sido sintetizada recientemente en el libro de S. James (1999), que plantea todos los inconvenientes de la aplicabilidad del concepto celta a la realidad protohistórica de las Islas Británicas.

Otra visión distinta en torno al tema de la etnicidad es desarrollada parcialmente por Renfrew (1990: 178), aunque él mismo la acabará desechando y enfatizando la anterior. Renfrew pone el ejemplo de los LoWiili, un grupo de África que no tenían consciencia de su propia identidad étnica, ni poseían un etnónimo con el que denominarse, pero cuya existencia y entidad étnica quedó plasmada por el antropólogo Jack Goody. Esta perspectiva es una derivación de la anterior. Mientras Barth situaba el foco de la etnicidad en las relaciones sociales y en la selección del individuo, Cohen (en Eriksen 1993: 45; también Jones 1997: 74 y ss.) considera que la etnicidad "es una forma organizativa, que puede ser reconocida o no por los propios agentes”. En esta visión, se destacan los aspectos más estructurales de la etnicidad. Esta es un tipo de organización política a través de la cual los grupos humanos alcanzan y mantienen el acceso a determinados recursos o fuentes de poder. Cohen pone el ejemplo del monopolio de los inmigrantes Hausa, en la ciudad Yoruba de Ibadan (Nigeria occidental), que en un corto periodo de tiempo lograron monopolizar el comercio de ganado a través de la solidaridad étnica. Esta solidaridad se expresaba a través de una cultura compartida y de una cohesión religiosa (en este caso, musulmana ortodoxa) (Eriksen 1993: 45-46). La perspectiva

1. S. Jones sin embargo clasifica a Barth como instrumentalista. La clasificación que yo admito aquí es la de Eriksen (1993) y la de Cohen. 
de Cohen, y la anotada por Renfrew a través de los LoWiili es una aproximación instrumentalista y objetivista al tema de la etnicidad. Las identidades étnicas se desarrollan en respuesta a requerimientos funcionales y organizativos, y pueden no ser conscientemente asumidas como tal por los seres humanos. Son las condiciones contemporáneas de los individuos las que hacen que emerjan las identidades, o que se activen. Por ejemplo, en el caso de los Hausa, el control del comercio de ganado. Cohen también aborda los aspectos más emocionales de la etnicidad, que no sólo es una forma de organización política sino que también satisface las necesidades psicológicas de pertenencia de los seres humanos en todo momento (sólo hay que recordar la creciente pujanza de los nacionalismos europeos, teniendo en cuenta que el nacionalismo es un nuevo mitó que supone una identidad relacional, una relación metafórica de parentesco-Eriksen 1993: 107-108). Ya no tratamos con unas identidades étnicas predeterminadas, como era la visión de Barth y la admitida por Renfrew y la mayor parte de los arqueólogos, sino que las identidades étnicas surgen o se activan respondiendo a situaciones históricas determinadas. Además, se trata de una visión objetivista de la etnicidad, ya que rechaza la adscripción categórica subjetiva y consciente de los individuos como el criterio esencial de la identidad étnica. Frente a la libertad selectiva que proponía Barth (casi en un sentido boasiano), Cohen resalta los aspectos estructurales, las imposiciones culturales sobre los seres humanos. La etnicidad es observable a través de características determinadas de organización social y política. Estas características toman como instrumento de cohesión determinados aspectos culturales que refuerzan estos lazos sociales y políticos a la vez que satisfacen la necesidad de pertenencia y relación de los seres humanos, y se manifiestan socialmente a través de la identidad étnica (ibídem: 56). Estos aspectos culturales no tienen que ser necesariamente todo el bloque cultural: cultura material, religión, vinculación a la tierra, sino algunos de ellos estructural y contingentemente seleccionados como representativos de esa identidad.

Lo que quiero destacar con todo esto, es que la etnicidad no es una adscripción categórica. Esta es la versión que parece haber sido aceptada por la Arqueología, y es evidente que no es una aproximación útil, porque como he dicho, salvo por registros escritos no existe ninguna forma de aproximarnos a través de la Arqueología a este tema. Sin embargo, la visión de Cohen sí ofrece un campo de aplicación arqueológico. Puede existir una identidad étnica sin la aquiescencia de los agentes (Eriksen 1993: 45-46, 56-57), y esta puede ser aprehensible en el momento en que podamos identificar qué aspectos de toda la cultura son activados como elementos social y estructuralmente representativos de la identidad. Algunos autores, además, consideran que existe un vínculo muy fuerte entre identidad étnica, lengua, cultura y organización social (ibídem: 50). Una visión sintética de ambas posturas, la subjetivista y la objetivista, la aporta Giddens (1984). Los individuos estamos determinados en cierto modo por la estructura cultural y social, pero en cierto sentido tenemos libertad individual de elección-agency (tanto menos cuanto más relacional es nuestra identidad, o en otras palabras, cuanto menor es nuestra complejidad social y económica: Hernando 2002; Sökefeld 1999).

En cuanto a las aproximaciones a la etnicidad desde la práctica arqueológica, S. Jones (1997) realiza una síntesis de gran aplicabilidad metodológica al análisis y estudio de la cultura material. Su aproximación a la identidad étnica queda definida ya al comienzo de su obra: "Ethnic identity: that aspect of a person's self-conceptualization which results from identification with a broader group in opposition to others on the basis of perceived cultural differentiation and/or common descent" (Jones 1997: xiii). Y la etnicidad será por lo tanto "todos aquellos fenómenos sociales y psicológicos asociados con una identidad de grupo culturalmente construida...". A lo largo de su libro, esta autora analiza las anteriores teorías sobre la etnicidad, y aporta su propia visión de la misma, intentando en todo momento superar la dicotomía entre el primordialismo y el objetivismo. Mientras Eriksen (1993: 57) superaba esta dicotomía mediante la teoría de la estructuración de Giddens, Jones (1997: 88) lo hace a través del habitus de Bourdieu. Una identidad étnica puede ser históricamente contingente, pero se está determinada siempre por algo previamente existente. Como resultado, para ella la identidad étnica se desarrolla a través de la diferencia, es decir, se trata de una adscripción categórica consciente que se manifiesta en el momento en que la diferencia entre dos 
identidades étnicas y dos culturas es percibida por el individuo. La identidad étnica es algo por lo tanto culturalmente aprendido (como también admite S. James 1999: 74). Sin embargo, relativiza el carácter esencialista y estático aportado por el primordialismo a través del concepto de habitus de Bourdieu. En su aproximación sigue vigente la consciencia de la diferencia, y por lo tanto también la condición necesaria de un etnónimo conscientemente asumido por los individuos del grupo humano.

\section{UNA APROXIMACIÓN METODOLÓGICA}

Con todo lo anterior, creo que es posible realizar un acercamiento metodológico a la etnicidad en la protohistoria europea, desde una perspectiva antropológica que prime el objetivismo y por tanto la posibilidad de análisis de la etnicidad a través de los estudios de las culturas humanas del pasado. Es una realidad que todos los seres humanos poseen una identidad, tanto individual, es decir, de relación del ser humano con la realidad (Hernando 2002), como social, de relación del individuo con su grupo (Eriksen 1993: 10). A su vez, esta identidad social está determinada por el modelo de inteligibilidad del grupo humano al que pertenece el individuo, por su cultura en sentido extenso. Este modelo de inteligibilidad, tal como lo definiera Lèvi-Strauss (1999 [1962]: 62, 198 y ss) está estructuralmente determinado por la complejidad social y económica del grupo (Hernando 2002). Los grupos con menor desarrollo social y económico mantienen una correspondencia entre la naturaleza y la cultura. Es decir, el comportamiento de la naturaleza está regido para ellos por conductas humanas (Lèvi-Strauss 1999 [1962]: 319; Hernando 2002). Por lo tanto, conciben un universo social plano, en el que los seres humanos y la naturaleza comparten los mismos modos de comportamiento. Aunque se establecen diferencias entre los distintos grupos humanos, su naturaleza humanaanimal sigue siendo la misma. Sin embargo, cuando el nivel de complejidad es mayor, se establece una mayor separación entre naturaleza y cultura, entre naturaleza y seres humanos. A su vez, este universo humano ya no se hace paralelo a la naturaleza, ya no se trata de un universo social plano, sino que las diferencias entre los grupos humanos se conciben como esenciales, como innatas. La sociedad ya no es un universo natural en el que todos sus miembros comparten la misma naturaleza, sino que dentro de este universo social se establecen clasificaciones concretas. Lèvi-Strauss explica este cambio a través de la sustitución de la representación metafórica de las relaciones humanas en términos de relaciones entre especies, propia de los grupos con clasificaciones totémicas y similares, por una separación entre la naturaleza humana y animal, y dentro de la naturaleza humana una clasificación entre grupos. La naturaleza de estos grupos ya no es la misma, sino que se establece una clasificación de los mismos en función de "algunas propiedades diferenciales concebidas como hereditarias" (Lèvi-Straus 1999: 173). Cada grupo humano se considera de una naturaleza distinta a los demás, potenciando por lo tanto la endogamia o la exogamia restringida con otros grupos que se consideren de la misma naturaleza. De hecho, Lèvi-Strauss (ibídem: 182, señala que " $e l$ cambio restringido es una imitación de la endogamia en el seno mismo de la exogamia, puesto que el cambio restringido es propio de grupos que se consideran cerrados y cuyos cambios internos están replegados sobre ellos mismos". En suma, la etnicidad es un instrumento de clasificación del universo social que desarrollan todos los grupos humanos, destacando sobre todo en aquellas sociedades con escaso desarrollo del individualismo como modo de relación del ser humano con la realidad social y material. En estas circunstancias, el individuo estructura su modo de relación con la realidad social, con el universo social, a través de su identidad grupal. La etnicidad crea orden en un universo social que de otro modo estaría desordenado, y en el que la pertenencia a un grupo es esencial para la identidad del ser humano y para su supervivencia. Los sistemas de clasificación social se corresponden entonces con definiciones étnicas, que son las que sirven para ordenar el universo social del individuo, que de otra forma sería un marasmo caótico de relaciones sociales y grupales (Erikssen 1993: 60-62). En la actualidad, por ejemplo, esta necesidad de pertenencia 
inherente a todo ser humano (vide supra) asociada a la mayor individualización del mundo desarrollado, ha resultado en un resurgir efervescente del nacionalismo, que se ha convertido en una especie de parentesco metafórico que sustituye al sentimiento de pertenencia étnico de sociedades menos complejas (Hernando 2002; Eriksen 1993: 107 y ss.). La etnicidad es por lo tanto una herramienta de clasificación, que crea orden en un universo social desordenado, dando al individuo modos de comportamiento intra e intergrupal que modelan la práctica social constantemente (ya sea a través de estigmas, etc. Eriksen 1993: 22-32). Además, para ser socialmente útil la etnicidad parte de " a shared habitus [which] engenders feelings of identification among people similarly endowed" (Jones 1997: 90). Es decir, se apropia de símbolos que están escogidos de las previas condiciones objetivas de vida, pero no arbitrariamente, sino de las experiencias diarias (ibídem). La etnicidad, por lo tanto, es históricamente contingente en cuanto a su significado y su manifestación y desarrollo concreto, está determinada por las condiciones materiales y sociales previas, pero sigue siendo una herramienta social presente en todos los grupos humanos. Incluso cuando un sistema de clasificación social étnico se rompe, por cambios en las condiciones históricas de su existencia, surge otro que lo sustituye tomando partes del anterior y dotándolas de nuevos significados: Lèvi-Strauss (1999 [1962]: 231-232). Su manifestación es constante en la práctica diaria, y ésta es la que establece diferencias de grado, puesto que la manipulación política de la etnicidad puede llevar al nacionalismo, o a la gestión de otras identidades, grupales, de género, de clase... (Eriksen 1993: 4-9). No existe un solo grado de etnicidad, sino que ésta tiene diferentes niveles o grados histórica y situacionalmente contingentes (ibídem: 41-45; ver también Jones 1997: 87).

Todos los individuos poseemos ambas identidades, independientemente de que ésta última, la de relación con el grupo, que es la que otorga cohesión interna al grupo en la gestión de su cultura (Lèvi-Straus 1999 [1968]), se exprese conscientemente a través de un etnónimo o no. Además, ambas están estructuralmente relacionadas, ya que los grupos humanos con una menor complejidad social y económica tienen una identidad individual (en el sentido de relación del ser humano con el mundo) mucho más relacional, es decir, mucho más determinada por la identidad social del grupo humano al que pertenecen. Es decir, frente a la opinión sostenida por Renfrew (1990) o más recientemente por James (1999: 69), la ausencia de un etnónimo no implica la inexistencia de una identidad grupal. De hecho, muchos de nosotros en la actualidad actuamos respondiendo a identidades étnicas de las que apenas somos conscientes. Es esta identidad de grupo la que se manifiesta en el momento del contacto con otro grupo: es decir, la identidad con tu grupo se manifiesta a través de la diferencia, y es entonces cuando se dice que tienes una identidad étnica. Al fin y al cabo ambas son lo mismo. La etnicidad es la manifestación concreta y contingente de la identidad de grupo, de la identidad étnica. Esta diferenciación entre una y otra resulta más bien de nuestro propio análisis del proceso. De hecho la identidad étnica se manifiesta en la práctica cotidiana constantemente, mediatizada por el contexto y la situación concretas (Jones 1997: 113-125).

Por otra parte, las identidades étnicas se estructuran a la manera de un lenguaje (Sökefeld 1999). De la misma manera que el habla es la materialización del lenguaje, y le precede siempre históricamente, aunque el conocimiento del lenguaje sea necesariamente previo a su materialización (Derrida 1989 [1968]: 47,51), la materialización de la etnicidad en los procesos de contacto entre grupos étnicos es siempre históricamente anterior a la articulación de la etnicidad como un sistema de significación o un lenguaje, aunque es preciso que este lenguaje sea previamente conocido para poder materializarlo.

James (1999: 74, 77) afirma que existen grupos humanos sin una identidad étnica, es decir, grupos humanos que no son etnias. Como ejemplo, pone el estado de las comunidades humanas de las Islas Británicas durante los primeros tiempos de la Edad del Hierro. Estas comunidades, de escaso tamaño, sedentarias pero con poco nivel complejidad social y económica, sin alto grado de especialización, estarían organizadas básicamente a través del parentesco (ibídem: 80 ), serían sociedades segmentarias. Es precisamente el modo de gestión de este parentesco lo que queda determinado a través de la identidad étnica, y ésta a su vez responde al 
modelo de inteligibilidad del grupo en cuestión. ¿Son todos los grupos humanos susceptibles de ser considerados parientes? Hasta dónde alcanza el parentesco, espacial y temporalmente, y hasta dónde es socialmente efectivo, está codificado mediante la etnicidad como instrumento de clasificación. Otro ejemplo del mismo autor es el de la Cristiandad Occidental en la Edad Media: "Si "celta" tiene alguna utilidad para la Edad del Hierro, entonces es análogo a un término como la "Cristiandad Occidental" para Europa hace cinco siglos-un nombre para un grupo de muy variadas culturas con algunas características y valores compartidos, adquiridos a lo largo del tiempo a través de contactos mutuos, pero con ningún sentido de identidad compartida, étnica o nacional" (James 1999: 80, traducción de la autora). En mi opinión, lo que se confunde en estos casos es la existencia de la identidad étnica como instrumento social, manifestada a través de los procesos sociales, y la idea de la identidad étnica como una transposición de nuestro actual sentido de la identidad, categórico y monolítico, además de políticamente estructurado y culturalmente justificado. La "Cristiandad Occidental" quizás no fue una identidad étnica monolítica, o en expresión de S. Jones (1997), no puede ser analizada con aproximaciones simplistas de "cookie-cutter", y tal vez no fue igualmente percibida por las diversas comunidades humanas que la compartieron. La "Cristiandad Occidental" sí puede ser considerada como la manifestación de un aspecto determinado de la identidad de grupo de los seres humanos de la Europa occidental, en este caso vinculado a una orientación religiosa. Este aspecto concreto de la identidad étnica de los seres humanos se manifestó materialmente en la existencia de lugares de culto, de iglesias, en toda la zona, e incluso con una homogeneidad de estilos que no se corresponde con la heterogeneidad cultural, social y económica que el autor menciona y que también existió. Este determinado aspecto de la identidad estuvo indudablemente marcado por otras identidades étnicas regionales, comarcales, clánicas, o de cualquier otro tipo. Si consideramos que la etnicidad es un sistema de clasificación no absoluto, sino estructurado como un sistema de significación (Lèvi-Strauss 1999: 323, 330; Sökefeld 1999: 422-424), sí es posible afirmar que la identidad de la "Cristiandad Occidental" existió como identidad étnica, por cuanto funcionó como herramienta social para cohesionar, en determinados niveles y a partir de la religión, al occidente europeo. No hay que olvidar que a pesar de la fragmentación social y política de la Edad Media, este aspecto de la identidad fue capaz de superar este estado fragmentario y movilizar a miles de seres humanos en la consecución de un mito religioso: me refiero a las cruzadas de los ss. XI-XIII d. C. para recuperar los Santos Lugares. Otra cosa es que esta identidad adquiriese una nueva significación a diferentes niveles, al estar marcada (en sentido lingüístico) por otras identidades. Así, un individuo podría pertenecer y sentirse profundamente cristiano. En este caso, la identidad cristiano occidental es un instrumento de clasificación extenso: serviría para cohesionar a esta identidad frente a otra potencialmente similar: lo no cristiano, como percepción del mundo musulmán. A otros niveles, esta identidad no se activaría pero permanecería latente, y sería más importante, por ejemplo, la identidad regional, y entonces la identidad cristiana occidental pasaría a un segundo plano, activándose otra identidad más restringida; pero aun dentro de ésta, cabría establecer otras identidades: la identidad comarcal, la local frente a otras aldeas, etc. (algo similar en el ejemplo de los Pathans de Afganistán, en James 1999: 73). En este sentido, la etnicidad es un lenguaje de clasificación. No se trata por lo tanto de establecer unidades concretas, que estén subsumidas unas dentro de otras, sino de analizar un lenguaje, un código que ordena el universo social del individuo. Este lenguaje existe en todas las culturas y en todos los grupos humanos, independientemente de su complejidad social y económica. Todos los mencionados son diferentes grados de significación étnica (Eriksen 1993: 41-45), situacional e históricamente contingentes.

¿Pueden existir grupos humanos que no tengan una identidad étnica? Recientemente se ha demostrado que existen una serie de factores que determinan la identidad de los seres humanos (Hernando 2002). La complejidad social y económica, el grado de especialización de la sociedad y el dominio de las condiciones materiales de la misma son condiciones estructurales que determinan en última instancia la relación del ser humano con la realidad material y social. A mayor grado de complejidad de los grupos, con la aparición 
de mayor especialización y por lo tanto con un aumento de las interconexiones intra sociales del individuo, éste va desarrollando un mayor grado de individualidad. En grupos en los que estas condiciones son menores, es decir, con una complejidad menor, la identidad de los seres humanos se ve mucho más determinada por las relaciones con el grupo humano en el que viven (Ibídem). Es decir, son identidades relacionales, y la identidad étnica es mucho más determinante que en grupos humanos con mayor grado de individualización. Por lo tanto, respondiendo a la pregunta de si es posible que existan grupos humanos en los que no haya una identidad étnica, la respuesta es negativa. Todos los grupos humanos tienen una o varias identidades étnicas (como refleja la cita introductoria). Lo que varía es la importancia proporcional de la identidad individualizada y de la relacional. Para que exista un dominio de la individualidad, y la identidad de grupo o étnica tenga menor peso en la conducta, es decir, para que un individuo se encuentre en condiciones de sobrevivir sin depender psicológica y materialmente del grupo humano en el que vive, es necesario que haya desarrollado una identidad individualizada. Esto, sin embargo, sólo sucede en sociedades con un elevado control de la realidad material, una elevada complejidad social y económica y por lo tanto con un universo social y un lenguaje social pobladode individuos, y no de grupos humanos (Hernando 2002; Elías 1990, 1993).

\section{LOS CELTAS}

Los grupos humanos del occidente europeo, que los autores clásicos denominaron celtas, ya fueran jefaturas simples o complejas, presentarían una identidad relacional aunque con un individualismo algo más desarrollado, sobre todo entre las elites, y por tanto tendrían una identidad étnica a nivel grupal bien definida. Es decir, a lo largo del Bronce Final y de la Edad del Hierro, los parámetros de relación con la realidad, el modelo de inteligibilidad de los individuos, estaría estructuralmente relacionado con el desarrollo social y económico del grupo al que pertenecen, y al mismo tiempo su modo de relación con la sociedad y con el restode los seres humanos, estarían también estructuralmente relacionados con el modelo de inteligibilidad que ordena según unos parámetros étnicos su universo social. Quiero resaltar que esta identidad étnica no tiene por qué ser conscientemente asumida por el individuo para existir, ni tiene que significar lo mismo para todos los individuos que la comparten. Esta identidad étnica es un lenguaje que ordena el universo social en el que se desenvuelve el individuo y determina el alcance, grado y posibilidades de interrelación entre éste y los miembros de su grupo, pero también entre éste y aquellos que no son miembros inmediatos de su grupo, o son totalmente ajenos a él. Lo que pretendo decir es que la identidad celta podría haber surgido como una categoría del universo social en sentido extenso: es lo que se activaría en el momento de establecer relaciones entre estas comunidades del occidente europeo. De hecho, es la posibilidad de que estas relaciones entre todos estos diversos grupos humanos heterogéneos fuesen posibles, puesto que en sociedades poco complejas la etnicidad influye activamente en la vida social, económica y política de los grupos humanos (Jones 1997: 125). Algo similar a lo que proponía para la Cristiandad Occidental (vide supra), en sentido comparativo y sin que esto implique la pervivencia de la misma identidad y de las mismas características diferenciales entre ambos términos de la comparación.

Desde el Bronce Final está atestiguada la existencia de una serie intensa de contactos entre las comunidades de la fachada atlántica, y entre éstas y las comunidades centroeuropeas (Almagro-Gorbea 199; Cunliffe 1995, 1997; James 1999: 87; Kristiasen 1998; Ruiz-Gálvez 1998; Waddell 1995). La manifestación en la cultura material de estos contactos se ve reflejada en la amplia disposición de la misma tecnología del bronce atlántica en las zonas citadas, como lúnulas irlandesas en yacimientos portugueses, las espadas pistiliformes y luego las lengua de carpa, torques de tipo Tara, o materiales centroeuropeos, etc. El alcance y la importancia de estos contactos no son determinables exclusivamente a través del registro arqueológico, puesto que no existe una relación directa entre semejanza o diferencia en el registro y el grado de interacción de las 
comunidades (Jones 1997: 115). Por otra parte, no sólo por tierra se establecerían estos contactos, sino que la mayor parte de ellos se realizarían por mar, dadas las facilidades de la navegación frente al transporte terrestre (James 1999: 87 y ss.; Ruiz-Gálvez 1998: 101-113). Para que esta amplia red de relaciones, desarrollada de forma variable en un amplio marco espacio-temporal, funcionase, el papel de los contactos debía estar estructuralmente integrado en la vida social cotidiana. Esto no quiere decir que todos estos grupos humanos participasen activamente de este comercio o de estos contactos, sino que la especialización de algunas de estas comunidades, o de ciertos miembros de ellas, en el comercio (por ejemplo North Ferriby, Ruiz-Gálvez 1998: 77-79, 87-88) estaría estructurada por las relaciones sociales intra e intergrupales.

Por otra parte, se ha supuesto que los sistemas de organización social de estos grupos serían exogámicos. M. Ruiz-Gálvez (1998: 39 y ss.), siguiendo al antropólogo J. Goody afirma que en grupos en los que existe cierta intensificación económica, con sistemas agrarios complejos, el sistema matrimonial más extendido sería el de matrimonio con dote. Además, se ha supuesto que entre estas comunidades atlánticas del Bronce Final se realizarían intercambios de mujeres, y que éstos se manifiestan en el registro arqueológico a través de objetos foráneos, por ejemplo el torques tipo Tara de Castrogeriz (Burgos) (Delibes et. Al. 1995. 45-59). Siguiendo a Rowlands, estos intercambios serían del tipo crow-omaha (Ruiz-Gálvez 1998: 39-40). Básicamente este tipo de intercambios exogámicos se establecen entre clanes que intercambian sus mujeres, y que estructuran estos intercambios mediante unas leyes de exogamia amplias, según las cuales "todos los clanes que no están expresamente prohibidos están permitidos" (Lèvi-Strauss 1999: 166). Lo que viene a significar este intercambio de mujeres es que, si bien los diferentes grupos humanos o clanes se diferencian unos de otros y se relacionan mediante las leyes de la exogamia, la posibilidad de intercambiar las mujeres entre ellos supone que, en última instancia, la naturaleza de éstas es la misma para todos los grupos. Las mujeres son naturalmente idénticas en la medida en que es posible intercambiarlas para la reproducción de los clanes, pero son culturalmente distintas, puesto que las posibilidades de los intercambios y por lo tanto las diferencias entre las mujeres que se intercambian están culturalmente establecidas (ibídem: 183-188). La aproximación más común al tema es que estos intercambios de mujeres se producen entre las elites, para asegurar el control del trabajo sobre la tierra, y el acceso y control de las rutas comerciales que les proporcionan los bienes de prestigio que les mantienen en el poder (Ruiz-Gálvez 1998: 40; 1992). Sea esto así, o bien estos intercambios se produzcan también en otros niveles sociales, lo cierto es que la posibilidad de establecer intercambios de tipo parental no está única y exclusivamente determinada por los intereses económicos y de poder de las elites. Los intercambios, incluyan las mujeres o no, no crean vínculos o alianzas entre comunidades $e x$ nihilo y arbitrariamente, sino que a la inversa son la manifestación social de que entre las comunidades que intercambian mujeres existe un vínculo social previamente existente (N. Thomas 1991: 7-34). El universo social de las comunidades que intercambian mujeres es por lo tanto el mismo, son comunidades unidas por la misma naturaleza. Las mujeres no son objetos materiales que puedan intercambiarse tal como las espadas o hachas del Bronce Final (tal como acertadamente apunta M.J. Bóveda 1996), sino que su intercambio simboliza que las comunidades que lo establecen tienen un vínculo en común, un vínculo identitario (identidad en el sentido de semejanza). No es suficiente con que existan elites y existan rutas comerciales: tiene que estar estructuralmente integrada la posibilidad de intercambiar seres humanos para que este intercambio sea posible, es necesario que ambas cosas vayan juntas (Lèvi-Strauss 1999: 24).

Los intercambios de mujeres y las redes comerciales no crean vínculos sociales entre grupos humanos previamente inconexos, sino que a la inversa, las conexiones sociales previamente existentes entre los grupos humanos estructuran las posibilidades de estas redes. Determinan si es posible intercambiar o no mujeres entre ellos, si es posible comerciar y qué objetos determinados de la cultura material, o incluso qué conocimientos técnicos, pueden ser alienados (Thomas 1991: 35-82). Además, la estructuración de los contactos entre estas comunidades determinaron la posibilidad de los contactos con los comerciantes mediterráneos en la transición a la primera Edad del Hierro, puesto que las "formas de interacción de los grupos humanos 
emergen de formas políticas y económicas ya existentes...creando por lo tanto condiciones previas para intrusiones coloniales posteriores" (ibídem: 88, traducción de la autora). Esto explica la integración en el sistema mundial de Fiji, y la parcial auto-exclusión del mismo de las Marquesas durante los siglos XVIII y XIX (Thomas 1991: 83-124): en el primer caso la jerarquización social estaba asociada a la externalidad, al comercio con objetos que pueden ser nuevos, mientras que en el segundo la competición y la estructura de poder se mantenía a través del despliegue de productos alimenticios, elaborados siempre por las propias comunidades. En el primer caso, el comercio se establece como una posibilidad socialmente relevante, en el segundo, esta posibilidad se limita a casos excepcionales, o a una actividad no integrada en la vida social de la comunidad (Thomas 1991: 93). La manera en que las comunidades indígenas se integraron en los sistemas mundiales del Bronce Final y la Primera Edad del Hierro, estaba condicionada por el papel que el comercio y la interacción con otros grupos tenían en el seno de las comunidades. En este sentido, una identidad étnica celta no justifica una homogeneidad de actitudes respecto al comercio, sino que es la relación de esta identidad con las demás identidades étnicas o de grupo (locales, clánicas...), unida a contingencias históricas y geográficas (proximidad y control de materias primas, relativo aislamiento respecto a vías de comunicación...) la que determina actitudes diferenciales en cuanto al comercio y al contacto con grupos nuevos, que se ven reflejadas en el registro arqueológico. En este caso de aislamiento, la significación de la identidad celta simplemente, no se activaría.

En cuanto al origen de lo celta como un nivel de identidad étnica, la perspectiva más apropiada al respecto es la de celticidad acumulativa definida por Hawkes (1973), y matizada como celticidad acumulativa recíproca por Renfrew (1990: 199). Como afirma este último, es muy posible que el origen de las lenguas historiográficamente denominadas celtas se encuentre en la interacción continuada entre comunidades políticas similares, con diferentes intensidades en el espacio y el tiempo (ibídem: 200). La identidad celta se estructuraría de la misma manera, dependiendo de la intensidad de estas interacciones su peso específico respecto a la identidad local. Estos contactos múltiples y estructuralmente integrados en la vida intra e inter-grupal bien pudieron haber provocado el surgimiento de características estructurales comunes, percibidas posteriormente por el otro, el mundo griego y el mundo romano, bajo el apelativo de celta. Esta identidad celta en sentido extenso se entendería como significante de las posibilidades de interrelación entre comunidades que se consideran, de alguna manera, estructuralmente integradas dentro del mismo orden social. Ya sea que esta identidad se manifieste o esté manipulada por las elites, tal como la identidad cristiana occidental fue canalizada por las elites religiosas para emprender las cruzadas; o bien sea asumida por amplias capas de la sociedad. Además, el surgimiento de esta identidad como catalizador de las interacciones explicaría la homogeneidad analizada por Dumézil (1958) para la ideología trifuncional indoeuropea de tipo celta, en contraste con otras ideologías indoeuropeas como la romana o la griega. A menudo se ha criticado el utilizar el modelo de Dumézil como herramienta antropológica de análisis para el mundo celta, afirmando que tanto griegos como romanos eran indoeuropeos y no eran celtas. Lo que se olvida aquí, es que este autor usaba el modelo trifuncional como una teología de forma similar proveniente del mundo indoeuropeo, una "mitología etiológica" que explicaría no sólo las similitudes, sino también las diferencias entre las diversas religiones o mitologías indoeuropeas desarrolladas en el tiempo y en el espacio (ibídem: 59). De manera que es este esquema conceptual, o modelo de inteligibilidad de origen indoeuropeo el que permanece en la ideología trifuncional de todas estas comunidades indoeuropeas, pero lo que varía es su plasmación concreta en el mundo romano, el védico o el celta, por poner algunos ejemplos. O desde una perspectiva estructuralista, un modelo de inteligibilidad en el que "los elementos no son constantes, sólo lo son las relaciones" (Lèvi-Strauss 1962: 86).

La manifestación arqueológica de esta identidad celta extensa, se encuentra en la materialización de contactos a larga distancia, en la estructuración social de la guerra (Parcero 1997), etc. Es decir, en aquellas condiciones de homogeneidad social y material que revelan variaciones en un mismo tema (James 1999: 82). Es un axioma ampliamente asumido que cultura e identidad no son una ecuación de igualdad, sino que 
una misma cultura (en este caso material) puede estar ocultando identidades diversas, y a la inversa, que diferentes culturas pueden estar organizadas a través de una misma identidad. Como afirma S. James (1999: 80, traducción de la autora): el occidente europeo se define "arqueológicamente en términos de diferencia y de tradiciones autónomas, cuyas semejanzas, indudables pero no universales, emergieron del contacto mutuo y de la convergencia, y no de raices compartidas heredadas". Este autor, y la mayoría de los autores europeos consideran esto hacia la eliminación de lo celta, en todo sentido (Calo 1997; Collis 1997; James 1999: 90; Peña 1997). Y sin embargo, es posible canalizar las diferencias culturales a través del lenguaje de la etnicidad, operando las semejanzas que el autor menciona en ciertas circunstancias, y dando prioridad a otros niveles de identidad, como la jefatura, el clan o la región, en otras circunstancias. Por otra parte, la identidad étnica no surge de raíces comunes ni de la homogeneidad cultural, sino que como sostiene Cohen (vide supra), es una herramienta social estructuralmente integrada en la vida cotidiana del grupo humano. Sólo nuestra concepción occidental de la identidad nacional, como resultado político de la identidad étnica, nos lleva a creer que todos los grupos humanos necesitan reificar y objetivar su cultura y su pasado para justificar su identidad (Eriksen 1993: 37-38,96). No es necesario por lo tanto acudir a migraciones masivas de grupos, ni a aculturaciones desde un foco original: la identidad surge como instrumento social de cohesión y clasificación, y para gestionar ciertos recursos que son importantes para el grupo o grupos humanos que la desarrollan.

En el lenguaje de las identidades que se empieza a estructurar a partir de los contactos intensos del Bronce Final, la identidad celta sería un significado que marcaría (en el sentido lingüístico de marca: Derrida 1989 [1968]: 47) los demás significados étnicos dotándolos de una nueva significación, en cada grupo humano, situacional e históricamente (para ver un ejemplo de la estructuración de las identidades étnicas como un lenguaje, Sökefeld 1999).

Por otra parte, es obvio que la identidad, sobre todo la identidad étnica, no es un concepto inmutable, sino sometido a los cambios paralelos de la sociedad, al devenir histórico y a los derivados de la práctica social. La estructura que esquematiza la identidad del grupo está siempre sujeta al devenir y al cambio (Lèvi-Strauss 1999 [1962]:229-233, 339 y ss.), reconstituyéndose constantemente para dar coherencia a la vida social y al universo ordenado de los grupos humanos (ibídem) La identidad celta no es un concepto inmutable, ni en el espacio, ya que ejerce de marca de las diversas identidades con las que entra en el sistema del lenguaje étnico; ni temporalmente, puesto que el significado de la identidad es históricamente contingente (ibídem, James 1999: 75, 77). Por ejemplo, durante la transición a la Primera Edad del Hierro la identidad celta habría perdido importancia a favor de las diferentes identidades regionales o locales, que explican un desarrollo local de las tradiciones anteriores en las diferentes culturas castreñas de la fachada atlántica (Collis 1996; James 1999: 87-90; Peña 1997), activándose nuevamente durante la Segunda Edad del Hierro y el periodo de La Tène.

\section{NOSOTROS/ELLOS: GRIEGOS/CELTAS}

Todo lo anterior puede explicar las diferentes acepciones históricas del concepto celta de las fuentes clásicas. Como se ve en la Figura 1, en un primer momento el mundo mediterráneo otorgó una identidad general a todos aquellos grupos humanos del occidente y norte europeo. Esta identidad otorgada desde fuera reflejaría una dualidad: aquellos aspectos comunes de las comunidades descritas, y aquellos que las diferencian de quien hace la descripción. Este nombre de celtas que aparece en las primeras fuentes clásicas responde a cierto nivel de clasificación de los autores griegos que las elaboraron. Como hemos visto, los seres humanos elaboran clasificaciones tanto de la realidad material no humana, como de la realidad humana en la que están inmersos (Lèvi-Strauss 1999 [1962]: 24-25). Pero para clasificar algo es necesario conocerlo de una 


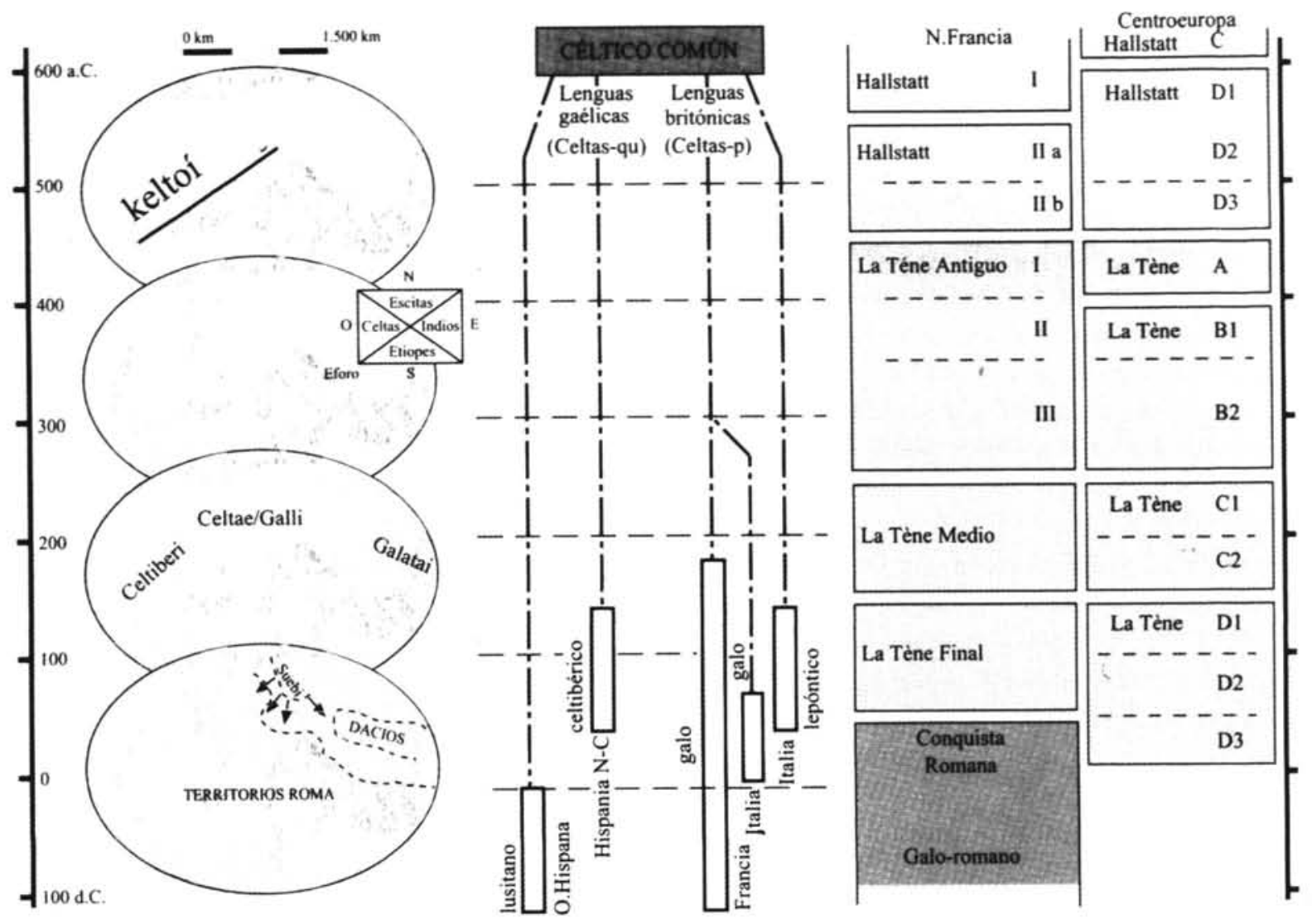

Fig. 1. Correlación de los datos de las Fuentes clásicas, las lenguas célticas antiguas y las culturas arqueológicas en la segunda mitad del I mil. a.C. (Ruiz Zapatero 2001: 85, el esquema lingüístico, según J. Untermann).

manera concreta, es decir, conocer sus propiedades intrínsecas y su significación en el entramado de relaciones de significación con elementos del mismo orden (otras identidades, otros grupos humanos) ode orden distinto en el que está inmerso (prácticas sociales, rituales...) (ibídem). Además, dentro de este universo social, los seres humanos no tenemos una sola identidad, sino que son diversas las identidades que se activan según las relaciones o la situación social en la que se encuentra inmerso el individuo. Existen diferentes órdenes de identidad según el grado de diferencia que se active situacional e históricamente. Según Eriksen (1993: 66 y ss.), en sociedades complejas, multiétnicas, funciona una especie de taxonomía étnica que pasa de los principios digitales de inclusión/exclusión (nosotros/ellos) a principios analógicos (nosotros/vosotros) en los que funcionan diversos grados de diferencias: percibimos gente que es "más o menos como nosotros", o gente que es "absolutamente diferente de nosotros" y los clasificamos en distintos grados de semejanza o diferencia. Por ejemplo el mundo griego, dentro de su diversidad geográfica y sociopolítica, era percibido también como una referencia identitaria más general. El individuo tenía una identidad social y política que lo vincularía a la polis, pero no dejaba de tener por otro lado una identidad griega, helena en sentido extenso (Bermejo 1978; Renfrew \& Bahn 1998: 177). Esta identidad helena se activaría, por ejemplo, con el contacto con el mundo escita, con el persa, o con el celta, a través de los principios digitales de la identidad. 
Ciertamente los griegos eran unos ojos acostumbrados a identificar entre diferentes pueblos, ya que no sólo todo el mundo ajeno era bárbaro, sino que sabían distinguir entre etíopes, escitas, persas y celtas. Esta denominación extensa de celta fue matizándose cuanto mayor fue el contacto del mundo mediterráneo con el occidente europeo. Las fuentes revelan posteriormente los nombres de diferentes grupos étnicos, de diferencias culturales entre ellos, pero el etnónimo celta sigue estando presente, en diversos grupos étnicos (los que entran en contacto con los massaliotas), o diferentes tribus (las que describe Estrabón para Hispania). Dentro de este modelo de aproximación arqueológica a la etnicidad, el punto clave está en que la etnicidad es percibida con la diferencia, en cierto sentido, la identidad étnica es activada con el contacto entre grupos humanos diferentes (Eriksen 1993: 1-15; Sökefeld 1999: 418). La diferencia es esencial para que se active empíricamente una etnicidad latente, y esta diferencia es mucho más percibida por aquellos grupos humanos que están en mayor contacto con otros grupos de su entorno. Cuanto mayor es el contacto con otros grupos, más se empiezan a desarrollar diferenciaciones analógicas de la identidad, ya no se trata de un universo social en el que estamos nosotros y luego lo demás, sino que existen grados de semejanza y de diferencia entre nosotros y vosotros, y entre vosotros mismos.

En este sentido, el comercio es un activador muy potente de la etnicidad, y es lógico que aquellas etnicidades latentes, percibidas como una unidad en un primer momento por el mundo clásico, se activasen en los momentos de mayores contactos comerciales. Estas identidades étnicas que los autores clásicos agruparon mediante la voz celta en un primer momento se activaron sobre todo durante Hallstatt, cuyo control del comercio del occidente europeo les llevó a una sociedad prácticamente estatal (Kristiansen 1998: 295). En estos primeros momentos de contacto intenso, los autores clásicos elaboraron una ordenación del universo social de la época enfatizando sobre todo las diferencias entre el mundo occidental europeo, con el que entraban en contacto, y su propio mundo. Su universo social estaba ordenado de manera muy esquemática, pero no deja de ser un orden real. Por ejemplo, nadie duda de la existencia del mundo persa, o de los escitas, y es obvio que África se conocía demasiado bien por los griegos como para creer que bajo la denominación común de etíopes los griegos, en concreto Eforo, no vieron más que unidad y no la diversidad real existente. Estoy de acuerdo con C. Renfrew (1993) y con G. Ruiz Zapatero en que estas denominaciones tenían un carácter geográfico muy marcado, obviamente una cartografía social se sitúa en el espacio de quien la describe, pero creo que su carácter cultural es también muy revelador, y desde luego un instrumento de primer orden para comprender la realidad social, el universo social en el que estaban inmersas las sociedades protohistóricas europeas. Nos sirven para conocer cuál era el grado de relación social existente entre estos mundos, tanto por parte de la percepción griega del mundo europeo, como al revés. Esta clasificación extensa de lo celta nos define que, en su orden o clasificación del universo social, el occidente era conocido en cierta medida, puesto que no se puede clasificar y dotar de un nombre algo que no se conoce. Pero al mismo tiempo indica un grado de clasificación poco desarrollado, puesto que dentro de las diferencias internas de aquello que se conoce lo que se resalta es aquello que es común. Se empieza a establecer un universo social digital: el mundo griego, y lo demás, que es diferente. Ahora bien, dentro de lo demás, de los otros, se establecen ciertas diferencias: lo celta, lo escita... Además, no se debe olvidar que existían unas relaciones comerciales estructuralmente integradas tanto en el mundo griego como en las comunidades protohistóricas occidentales (Kristiansen 1999; Ruiz-Gálvez 1998). Dentro de la percepción del mundo occidental europeo estas relaciones activarían sistemas de representación social en los que se primarían las diferencias de primer orden, las diferencias generales o digitales entre ambos mundos.

Pese a los cambios sociales y económicos estas identidades cristalizaron en la Segunda Edad del Hierro. Con razón el arte lateniense se ha calificado como la expresión de nuevas formas de relación social, política y económica (Kristiansen 1998: 296). Las identidades no surgen de la nada, y aunque a menudo resultan de un proceso de reconstrucción del pasado desde el presente, con lo que no es una condición sine qua non la existencia de raíces comunes para que surja una identidad, los orígenes de las mismas son históricamente 
reales (ver Jones 1997, y su aplicación del habitus de Bordieu; o Eriksen 1993 y su aplicación de la estructuración de Giddens). La identidad celta que se había ido gestando en el Bronce final, transformada con el mundo del Primer Hierro, con Hallstatt, unida a todos los cambios sociales y económicos, se transformaría en una nueva identidad a lo largo de la Segunda Edad del Hierro. A. Hernando (2002) afirma que nuestra identidad como seres humanos está determinada por nuestro aprendizaje (también James 1999: 75; Jones 1997: 89); al mismo tiempo, el aprendizaje es una relación social, de manera que los cambios en las relaciones sociales implican cambios en la identidad adquirida. Nuevas identidades étnicas se estaban fraguando en toda Europa Occidental, a medida que iban sucediendo cambios en las condiciones sociales y económicas. Por lo tanto, esta identidad celta estructuralmente percibida por los autores clásicos fue progresivamente modificada por el devenir histórico. Nuevas relaciones económicas surgieron, nuevas relaciones tanto entre los propios grupos humanos occidentales como entre ellos y el mundo clásico griego y romano. Y por tanto nuevos mecanismos de identidad fueron activados. Los autores clásicos siguieron usando la voz celta como instrumento de aproximación a muchas de estas comunidades, pero en un sentido distinto del anterior. El contacto interétnico era mayor, y por tanto mayores los grados de diferenciación analógica (nosotros/vosotros) que se podían establecer y activar.

\section{CONCLUSIONES}

No existe un único concepto o uso de la voz celta por parte de las fuentes clásicas, sino que su significación fue cambiando con el tiempo y fue concretándose más a medida que los contactos entre ambos mundos, el clásico, nuestra fuente, y el protohistórico europeo, nuestro objeto de estudio, se fueron acercando. Está claro que el análisis de las fuentes clásicas precisa de una exégesis exhaustiva, tal como afirma $\mathrm{C}$. Renfrew (1993: 178-183), o G. Ruiz Zapatero (2001: 79-84), pero esta deconstrucción de las fuentes no debe ser destructiva. La producción historiográfica interpreta los textos clásicos tomando dos posturas antagónicas: si se habla de celtas, es que había unos celtas y una identidad o un mundo celta real pero monolítico, o por el contrario, al hablar de celtas se define la posición geográfica de algo que las fuentes desconocen en realidad. Lo que se pretende es interpretarlas de la manera en que nosotros, arqueológicamente, percibimos la protohistoria europea. $O$ vemos homogeneidad absoluta, o disgregación absoluta, o hay celtas o no hay celtas. Tal vez pretendemos conocer desde el presente el universo social de la protohistoria mucho mejor que sus propios protagonistas. Esto choca con dos problemas de base: en primer lugar, la etnicidad no es algo que se pueda percibir directamente a partir de la realidad arqueológica, a menos que se opte por un paradigma histórico-cultural, cosa nada recomendable (estas visiones monolíticas de la identidad étnica, en la que una cultura material homogénea corresponde a un grupo humano cultural y étnicamente homogéneo siguen estando tácitamente vigentes, tal como ha demostrado S. Jones -1997-, o como a parece en Harding 2000: 1); en segundo lugar, la etnicidad es algo social y culturalmente creado que convierte en símbolos identitarios, no siempre conscientemente, a ciertos aspectos de la cultura, no a todos. Por lo tanto puede existir una misma cultura, en nuestro caso material, con diversas identidades étnicas, y por el contrario, diversas culturas que respondan a una misma identidad étnica.

La lingüística tiene un gran papel aquí. La denominación de celtas de las lenguas protohistóricas fue una creación historiográfica realizada en el s. XVIII. Ahora bien, esta definición tiene una base real irrefutable: en la misma época en que los escritores clásicos hablan tanto de celtas en sentido digital (norte y occidente europeo) como en sentido analógico (aquellas etnias cuyas diferencias internas se perciben, con las que están en contacto y describen), todos estos grupos humanos, que indudablemente tenían identidades étnicas, hablaban una serie de lenguas emparentadas entre sí. ¿Responde esto a una única lengua celta? La posibilidad de una multiplicidad de variedades dialectales habla también de una gran diversidad social y cultural (Ruiz 


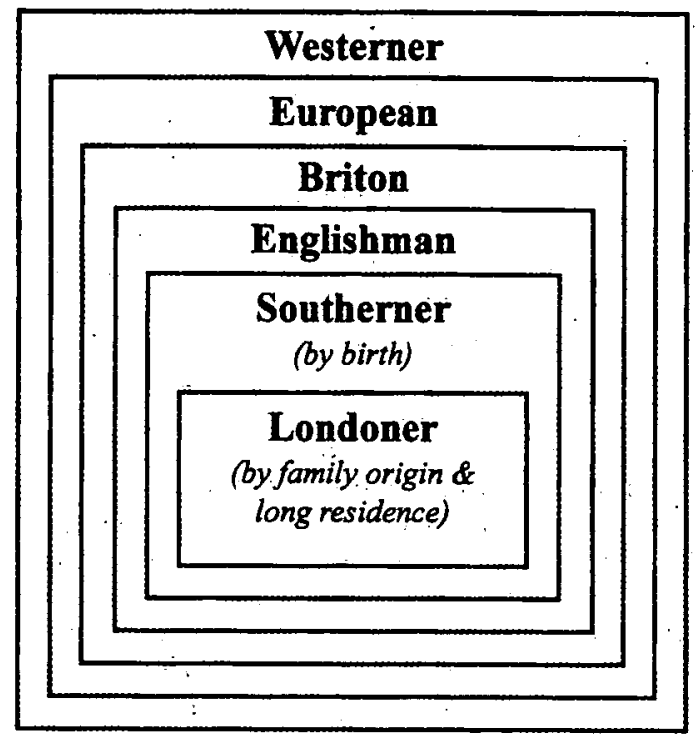

Fig. 2: Las identidades de grupo de S. James (1999: 70). Este sería un ejemplo de identidad múltiple, las identidades se ordenan según su importancia (Eriksen 1993: 152 y ss.)

Zapatero 2001: 85), si bien es cierto que siempre dentro de la misma familia lingüística y respondiendo estas variedades a los diferentes grados de interacción entre las comunidades humanas, en el espacio y en el tiempo. Se ha considerado que la lengua es uno de los elementos culturales más susceptibles de ser utilizados como símbolo de la identidad étnica (Eriksen 1993: 38-40; Jones 1993: 121; Renfrew \& Bahn 1998: 177.). Estas variedades dialectales responden, probablemente, a diferentes grupos étnicos, de mayor o menor alcance. Sin embargo, el Lusitano se ha interpretado como la lengua franca desarrollada a partir de los contactos de las comunidades del occidente europeo desde el Bronce Final (Ruiz-Gálvez 1991). De manera que la estructuración de las lenguas historiográficamente denominadas celtas podría representar los diferentes niveles de la etnicidad mencionados más arriba: las comunidades tendrían su propio dialecto, y sin embargo sería posible usar una lengua común en el momento en que se activen los vínculos que unen a estas comunidades étnicamente distintas, y al mismo tiempo étnicamente agrupables.

En un libro imprescindible para abordar el tema de lo celta para la protohistoria europea, S. James (1999: 70) reflejó en un gráfico la organización y la sistematización de sus identidades Figura 2. Tal como está realizado el gráfico, se supone que su identidad como occidental supondría buena parte de su identidad como individuo. Sin embargo, el mismo autor afirma que estas identidades que él posee no son idénticas durante todo el tiempo (ibídem: 70,72). Su identidad como individuo no es la suma aritmética de todas ellas, sino su estructuración: mientras una se activa, las demás permanecen latentes pero confiriendo, a la manera de un lenguaje, un sentido específico a todas las demás y a la que está activada. Se activan unas u otras, cobran mayor importancia dependiendo del contexto, de la situación, y muy probablemente habrán variado también de significado e importancia a lo largo de toda su vida. Su dibujo ya no sería comparable a una de esas muñecas rusas, sino a una estructura de significados multidimensional, en la que cada término existe y es significante en función de sus relaciones con los demás términos con los que está vinculado (Derrida 1989 [1968]; Sökefeld 1999). Figura 3.

La identidad no está indisolublemente unida a la cultura, ésta puede permanecer mientras aquella cambia, o viceversa. Nuestra cultura ha cambiado durante el último siglo de manera exponencial, pero las identidades 


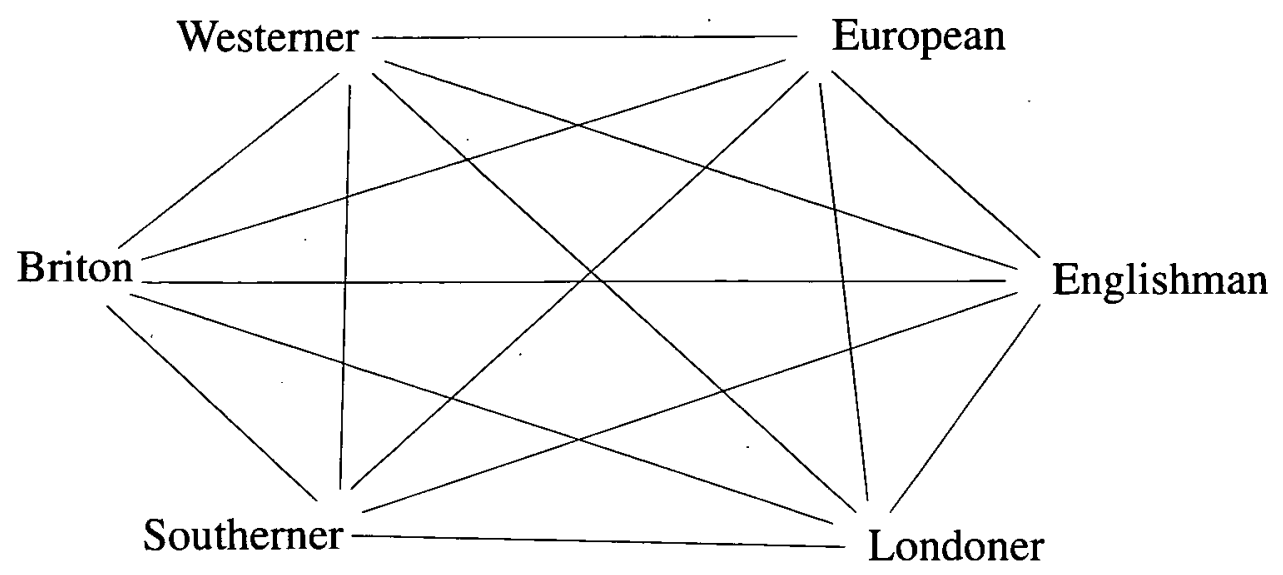

FIGURA 3: Estructuración de las identidades del cuadro anterior como un lenguaje de identidades múltiples, cuya importancia es contextual y situacional (Eriksen 1993: 153). El significado de cada identidad se sitúa en el espacio que queda delimitado por las relaciones con los demás términos. Así, una identidad no tiene significado por sí misma, sino que el significado está marcado por las relaciones que mantiene con todos los demás elementos significativos del sistema. Cualquier variación en los elementos relacionales del sistema provocará variaciones de significación en todos los demás. Tomado de la teoría de La Différance

(Derrida 1989 [1968]).

conservan su etnónimo, o nombre nacional, aunque ser inglés o europeo hoy no signifique lo mismo que hace ochenta años. Lo que sí permanece claramente en su esquema es el concepto de orden: en su caso las identidades están ordenadas según un criterio geográfico. Si un ser humano en el s. XX, dentro del mundo occidental europeo, y como hemos visto con un alto grado de individualismo como ninguna sociedad ha conocido, es capaz de dibujar sus identidades, es decir, si es capaz de dibujar un universo social en el que los individuos se agrupan en categorías, ¿qué importancia no tendría esta clasificación para un ser humano con una identidad mucho más determinada por su pertenencia a un grupo? Y no sólo eso, sino que el orden del universo social no se limita al grupo al que se pertenece, lo trasciende y clasifica también a la realidad humana que lo rodea.

Abordar la interacción entre los grupos humanos de la protohistoria del occidente europeo desde una perspectiva de la identidad, es una aproximación muy útil, desde la cual nosotros desde el presente podemos percibir una categoría étnica en sentido extenso, en sentido estructural, aunque los individuos y los grupos humanos del pasado no fuesen conscientes de ésta. O incluso si lo fuesen, no deseasen hacerla manifiesta en el cien por cien de su cultura material y durante el cien por cien de su vida cotidiana, enfatizando en primer lugar otras identidades, por ejemplo la clánica. Coincido plenamente con G. Ruiz Zapatero cuando afirma que, básicamente, los primeros celtas quizá "fueron un mosaico de pueblos con algunos rasgos comunes, entre los cuales las lenguas emparentadas y las costumbres debieron ser mejor percibidas por los «ojos mediterráneos»" (Ruiz Zapatero 2001: 79). Ahora bien, una definición de tal calibre, que implica el conocimiento y una cierta relación social de los "ojos mediterráneos" con estos pueblos trasciende lo geográfico y, con una visión estructural, lingüística y objetivista de la etnicidad, sí podemos percibir como étnica esta identificación, aunque sea impuesta desde fuera. Eso sí, sin caer en el error de ver unos únicos celtas, un único mundo celta, inmóvil e inmutable geográfica y cronológicamente, unos "celtas fuera del tiempo y del espacio" (ibídem: 82). Pero también sin pretender trascender a las fuentes y afirmar que conocemos mejor que ellas su propia realidad y su universo social. 
Es esta estructura de las relaciones humanas, que se manifiesta a través de sistemas ordenados de clasificación social, en forma de identidades étnicas, lo que debe ser analizado a partir de las fuentes junto con los datos arqueológicos y linguísticos. Desde esta perspectiva, creo que sí es posible hablar de celtas históricos, como una estructura lógica antropológicamente objetivada a través de la ideología indoeuropea y percibida étnicamente por los escritores mediterráneos, quienes reconocieron e instrumentalizaron mejor que nosotros la vivencia de cierto modelo de inteligibilidad, en el que podían reconocerse parcialmente, pero también diferenciarse de manera sustancial (vide supra, respecto al modelo trifuncional indoeuropeo). Es decir, un mundo celta, que refleja la misma complejidad pero al mismo tiempo la misma homogeneidad que lo que hoy conocemos como mundo mediterráneo.

Las connotaciones ideológicas y políticas del término celta son de sobra conocidas (Armando Pita 1999; Ruiz-Zapatero 2001; Díaz Santana 2001). Ante esta situación, se han mantenido en la investigación mayoritariamente dos posturas antagónicas: o bien eliminar el concepto de la literatura arqueológica puesto que su instrumentalización lo ha desvirtuado, o mantenerlo en la literatura tal como ha venido siendo empleado hasta el presente. El significado étnico e histórico que defiendo del concepto celta quiero separarlo de cualquier otro significado, nacionalista o de cualquier otro tipo, que se le pueda añadir desde la perspectiva histórica y social del presente. El lenguaje es una proyección de la cultura, y por tanto como arqueóloga no puedo evitar que nuevos significados sean añadidos al concepto; lo que sí puedo señalar es que esta interpretación de lo celta protohistórico como identidad concierne al pasado, nunca al presente. La objetivación de lo celta corresponde aquí a un análisis estructural de la identidad y la etnicidad aplicado a la protohistoria, en el que la validez del concepto radica en su utilidad como instrumento de análisis de procesos históricos y en su realidad histórica en las fuentes clásicas. El concepto de identidad celta tal como he intentado definirlo se limita a la protohistoria europea occidental. Esto no significa bajo ninguna circunstancia que esta identidad se pueda relacionar con las diversas identidades existentes en el presente y que también se denominan celtas. La identidad celta aquí propuesta, no se corresponde con unos celtas como grupo étnico, social, político y económico homogéneo y monolítico tal como entendemos la identidad cultural o nacional en nuestra propia sociedad, y no es bajo ninguna circunstancia la raíz histórica objetiva de ninguna de las identidades celtas del presente.

\section{BIBLIOGRAFÍA}

ALMAGRO GORBEA, M. ( 1995 ): "Ireland and Spain in the Bronze Age", en J. WADDELL y E. SHEE TWOHIG (eds.), Ireland in the Bronze Age: 136-148. Proceedings of the Dublin Conference, April, 1995. Dublin, Stationery Office.

ARMADA PITA, X.L. (1999): "Unha revisión historiográfica do celtismo galego", Os celtas da Europa Atlántica. Actas de I Congreso Galego solve a cultura celta. (Ferrol, agosto 1997): 229-272. Ferrol, Ayuntamiento de Ferrol.

BERMEJO BARRERA, J. C. (1978): La Sociedad en la Galicia Castaña. Santiago de Compostela: Follas Novas.

BÓVEDA FERNÁNDEZ, J.M. (1996): “Cambalache”, Gallaecia 14-15: 611-622.

COLLIS, J. (1996): "Urbanisation in Atlantic Europe in the Iron Age", Gallaecia 14-15: 223-241.

COLLIS, J. (1997): "Celtic myths", Antiquity 71: 195-201.

CUNLIFFE, B. (1995): Iron Age Britain, B. T. Batsford, Ltd./English Heritage, London.

CUNLIFFE, B. (1997): The Ancient Celts. Oxford-Nueva York: Oxford University Press.

CRIADO BOADO, F. (1993a): "Límites y posibilidades de la Arqueología del Paisaje", SPAL 2: 9-55.

DELIBES DE CASTRO, G.; ROMERO CARNICERO, A. y MORALES MUÑIZ, A. (eds.) (1995):

Arqueología y medio ambiente. El primer milenio antes de Cristo en el Duero Medio, Junta de Castilla y León, Consejería de Cultura y Turismo. 
BEATRIZ DÍAZ SANTANA

DERRIDA, J. (1989 [1968]): "La Différance”, Márgenes de Filosofia. Madrid: Cátedra.

DÍAZ SANTANA, B. (2001): "Arqueología y política en la investigación protohistórica de Galicia", Complutum 12: 311-324.

DUMÉZIL, G. (1958) : L idéologie tripartie des Indo-Européens. Latomus Revue d'Études Latines, XXXI. Bruxelles (Berchem).

ELIAS, N. (1990): La Sociedad de los Individuos. Ensayos. Colección Península/Ideas 14. Barcelona.

ELIAS, N. (1993): El proceso de la Civilización. Investigaciones sociogenéticas y psicogenéticas. México: Fondo de Cultura Económica.

ERIKSEN, T. H. (1993): Ethnicity and Nationalism. Anthropological Prespectives, London, Colorado, Pluto Press

GIDDENS, A. (1984): The Constitution of Society. Cambridge: Polity Press.

HAWKES, C. F. C. (1973): "Cumulative Celticity in pre-Roman Britain”, Études Celtiques 13, 2 : 607-628.

HARDING, A. F. (2000): European Societies in the Bronze Age. Cambridge-New York: Cambridge University Press.

HERNANDO GONZALO, A. (2002): Arqueología de la Identidad. Madrid: Akal.

JAMES, S. (1999): The Atlantic Celts. Ancient people or modern invention?. London: British Museum Press.

JONES, S. (1997): The Archaeology of Ethnicity. Constructing identities in the past and present. London: Routledge.

KRISTIANSEN, K. (1998): "The emergente of the European World System in the Bronze Age", en K. Kristiansen y M. Rowlands (eds.): Social transformations in Archaeology. Global and Local Perspectives: 287-324. London, Routledge.

LÈVI-STRAUSS, C. (1999 [1962]): El Pensamiento Salvaje. México: Fondo de Cultura Económica.

PARCERO OUBIÑA, C. (1997b): "The invisible warrior: warfare and Archaeology in the Indoeuropean Bronze Age", en F. CRIADO \& C. PARCERO (eds.), Landscape. Archaeology. Heritage, TAPA 2: 35-40, GiArPa, Santiago de Compostela.

PEÑA SANTOS, A. de la (1997): "Os pobos castrexos antes da conquista romana", en O feito diferencial galego na Historia, Vol. I: 143-191, Museo do Pobo Galego, Santiago de Compostela.

RENFREW, C. \& BAHN, P. (1998): Arqueología. Teorías, métodos y prácticas. Madrid: Akal.

RENFREW, C. (1990): Arqueología y Lenguaje. La cuestión de los orígenes indoeuropeos, Ed. Castellana 1990 ( $1^{a}$ ed. 1997). Barcelona: Ed. Crítica.

RUIZ ZAPATERO, G. (1993): "El concepto de Celtas en la Prehistoria Europea y española", en M. ALMAGRO-GORBEA \& G. RUIZZAPATERO (eds), Los celtas: Hispania y Europa: 63-76. Madrid, Editorial Actas.

RUIZZAPATERO, G. (2001): “¿Quiénes fueron los celtas? Disipando la niebla: Mitología de un collage histórico", en VV. AA., Celtas y Vetones, Avila: Edita Excma. Diputación Provincial de Avila.

RUIZ-GÁLVEZ PRIEGO, M. L. (1992): "La novia vendida: orfebrería, herencia y agricultura en la protohistoria de la Península Ibérica", Spal 1: 219-251. Sevilla.

RUIZ-GÁLVEZ, M. (1991): "Songs of a wayfaring lad", Oxford Journal of Archaeology 10 (3): 277-306. (1998): La Europa atlántica en la Edad del Bronce. Un viaje a las raíces de la Europa Occidental. Barcelona, Crítica.

SÖKEFELD, M. (1999): "Debating Self, Identity and Cultura in Anthropology", Current Anthropology 40, 4: 417-447.

THOMAS, N. (1991): Entangled Objects. Exchage, material cultura and colonization in the Pacific. London/Massachusets: Harvard University Press.

WADDELL, J. (1995): "Celts, Celtization and the Irish Bronze Age", J. WADDELL \& E. SHEE TWOHIG (eds.), Ireland in the Bronze Age. Proceedings of the Dubling Conference, April 1995: 158-169. Dublin. 